\title{
SPATIOTEMPORAL ANALYSIS OF SNOW DEPTH ON FIRST-YEAR ICE BASED ON FY3B/MWRI IN THE ARCTIC
}

\author{
Li Lele ${ }^{1}$, Chen Haihua ${ }^{1}$, Guan Lei ${ }^{1,2^{*}}$ \\ ${ }^{1}$ Department of Marine Technology, College of Information Science and Engineering, Ocean University of China, \\ Qingdao, China (lilele, chh7791, leiguan)@ouc.edu.cn \\ ${ }^{2}$ Laboratory for Regional Oceanography and Numerical Modeling, Qingdao National Laboratory for Marine Science and \\ Technology, Qingdao, China
}

Commission III, WG III/ 9

KEY WORDS: Snow Depth, First-year Ice, FY3B, MWRI, Spatiotemporal variation, Arctic

\begin{abstract}
:
As an important factor in the stability of the climate system in the northern hemisphere, the Arctic has recently attracted considerable attention. In the Arctic, most sea ice is covered by snow year-round, except in the snow-melting season. Given its high albedo and low thermal conductivity, snow cover on sea ice is considered a key component of amplified warming in the Arctic. However, in Arctic regions, the only products available are for snow depths on first-year ice. Therefore, this paper studies the temporal and spatial changes of snow depth on first-year ice in the Arctic using the snow depth on sea ice product determined from the Microwave Radiation Imager onboard the Feng Yun-3B satellite. We averaged the daily snow depth on first-year ice data to give monthly and annual values over the period 2011-2018, using flags for multiyear ice and melting points. Taking the 2012 data as an example, the analysis results show that the spatial distribution of snow depth in the monthly and annual data is similar over the whole first-year ice area. The snow depth basically decreases with latitude, and the distribution features exhibit little variation by month and year. The weekly mean snow depth on first-year ice begins to increase from October/November due to snowfall, and reaches a maximum value in late April/early May of the next year. There is no obvious law governing the inter-annual variation of snow depth in the Arctic from 2011-2018.
\end{abstract}

\section{INTRODUCTION}

Accounting for $5-8 \%$ of the global ocean surface area, sea ice is an important component and indicator of the global climate system because it has a relatively high albedo, which means it reflects nearly all short-wavelength radiation. As one of the coldest areas on earth, the Arctic is an important factor in the stability of the climate system in the northern hemisphere. Most of the sea ice in the Arctic is covered by snow year-round, except during the snow-melting season. Compared with sea ice, snow has a higher albedo and lower thermal conductivity. As a result, sea ice with snow coverage is a more effective insulator, which means that it can limit the energy and momentum exchange between the atmosphere and the ocean. In winter, snow produces a high albedo (up to 0.9) on the Arctic sea ice surface and has low energy absorption. However, snow restricts the impact of cold air on the sea ice, thus slowing its growth. In summer, melting pools form as the snow on the Arctic ice melts. These pools reduce the surface emissivity, absorb more energy, and accelerate the melting of ice. Therefore, snow is very important in the thermal energy balance process, and accurate sea ice and snow distribution measurements are significant factors in determining the water and heat exchange between the polar ocean and the atmosphere.

There are several operational products that include data for the snow depth on first-year ice in the Arctic. For example:

- The Advanced Microwave Scanning Radiometer-EOS (AMSR-E) and Advanced Microwave Scanning Radiometer 2 (AMSR2) snow depth products on sea ice, released by the National Snow and Ice Data Center (NSIDC) (Meier et al., 2018);
- The Scanning Multichannel Microwave Radiometer (SMMR) and Special Sensor Microwave/Imager (SSM/I) snow depth on sea ice product, released by the National Aeronautics and Space Administration/Goddard Space Flight Center (NASA/GSFC) (https://neptune.gsfc.nasa.gov/csb/index.php?section=53);

- The FengYun-3B/Microwave Radiation Imager (FY3B/MWRI) snow depth on first-year ice product in the Arctic, released by the Ocean University of China (Li et al., 2019a).

The abovementioned products are calculated using the same algorithm, which we call the AMSR-E algorithm for snow depth on first-year ice in the Arctic.

In this paper, we study the temporal and spatial variations of snow depth on first-year ice in the Arctic using the snow depth on sea ice product from FY3B/MWRI. The FengYun-3 satellite series are second-generation Chinese polar-orbiting meteorological satellites with substantially enhanced functionality and technical capabilities. MWRI is one of 11 sensors mounted on the FY-3B satellite, which was launched in November 2010 by the China Meteorological Administration/National Satellite Meteorological Center (CMA/NSMC). It is a total power passive radiometer with observation frequencies of $10.65,18.7,23.8,36.5$, and $89 \mathrm{GHz}$ and horizontal and vertical polarization for each frequency (Yang et al., 2011). 


\section{DATA}

The snow depth product from the Ocean University of China was used to analyze spatiotemporal changes in snow depth in the Arctic. This product uses brightness temperature (TB) data from FY3B/MWRI to retrieve the snow depth on sea ice in the Arctic. The data are from November 18, 2010, to April 30, 2019 (the sensor stopped running in September, 2019). The data product is based on the AMSR-E algorithm. Firstly, the FY3B/MWRI orbital TB data are cross-calibrated with the orbital TB products from Aqua/AMSR-E using a linear equation (Chen et al., 2019). The matching time window is set to $30 \mathrm{~min}$, and groups of calibration coefficients over 10 channels are computed for every month. The improved ASI algorithm is then used to retrieve the sea ice concentrations, which are used to calculate the snow depth on sea ice based on the MWRI TBs (Li et al., 2019b). To eliminate the effects of sporadic weather conditions, changes of grain size, and snow density, the snow depths are averaged over seven days with a spatial resolution of $12.5 \mathrm{~km}$ (for convenience, we call this the weekly snow depth).

To analyze the spatiotemporal changes, we averaged the daily snow depths on first-year ice to monthly and annual values, with flags for multiyear ice and melting points in the Arctic. The dataset used in this study covers the period 2011-2018.

\section{ANALYSIS}

The variations in snow depth are analyzed in terms of three factors: the monthly and annual distribution features of snow depth, the time series of the weekly average snow depth, and the variations in the monthly and annual average snow depth on firstyear ice in the Arctic.

\subsection{Snow Depth Distribution}

Firstly, based on the monthly data, we briefly analyze the spatial distribution features of the snow depth. Taking the 2012 data as an example, the monthly distributions are shown in Figure 1.
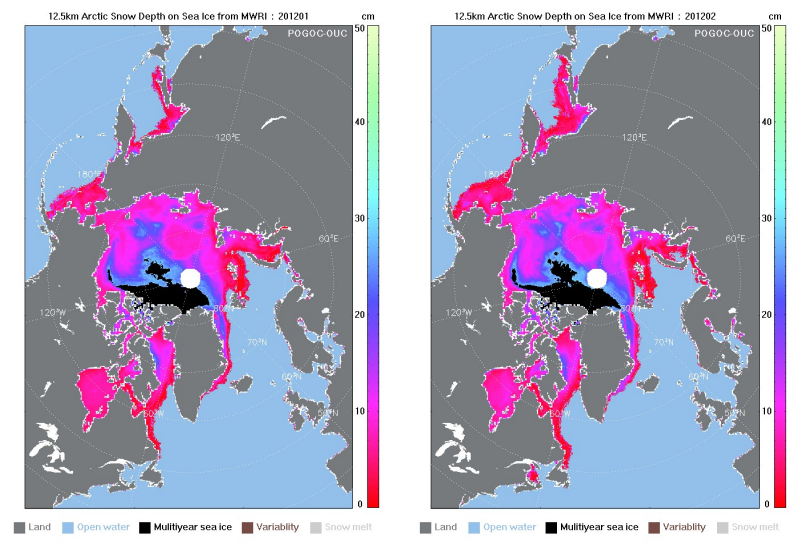
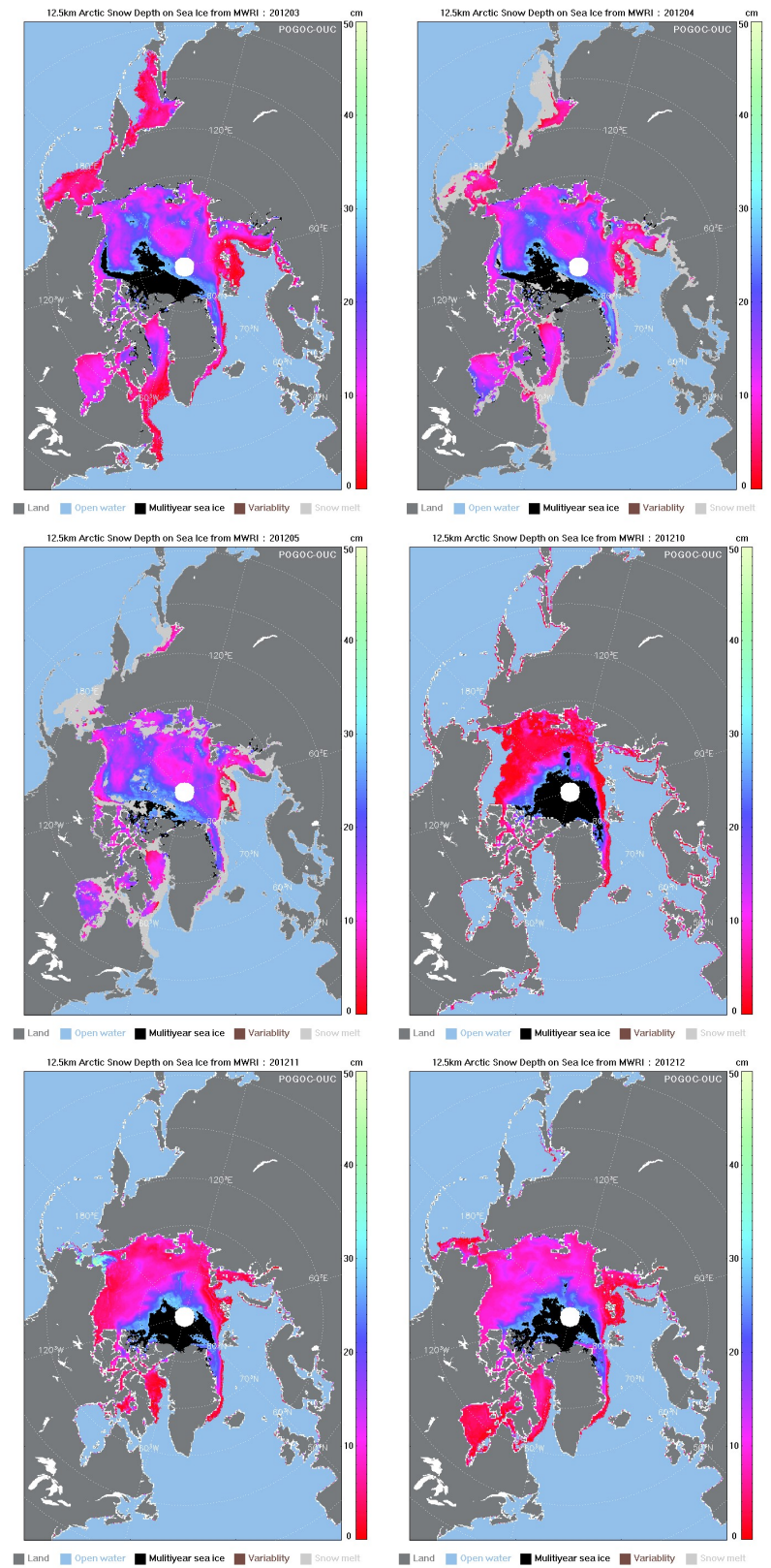

Figure 1. Monthly distribution of snow depth on sea ice in the Arctic in 2012

From Figure 1, we can conclude that:

1) The snow depth basically decreases with latitude away from the central Arctic, and the distribution shows little variation across the months, that is, the spatial distribution feature of snow depth is not directly related to time.

2) The snow depths in the north of Canada and Greenland, close to the central Arctic, are higher than those in the East Siberian Sea and Beaufort Sea, and the snow depths in the Kara Sea, Laptev Sea, and Chukchi Sea are lower than in the abovementioned seas in almost every month.

3) In April, the snow begins to melt from low latitudes and sealand boundary areas, and this phenomenon gradually extends to central areas. In October, new ice begins freezing and snow begins to accumulate. By the end of November, the snow covers the whole Arctic, and the snow depth begins to increase. 
Secondly, we average the snow depth on first-year ice for each year from 2011-2018. The distribution of annual average snow depth is shown in Figure 2.
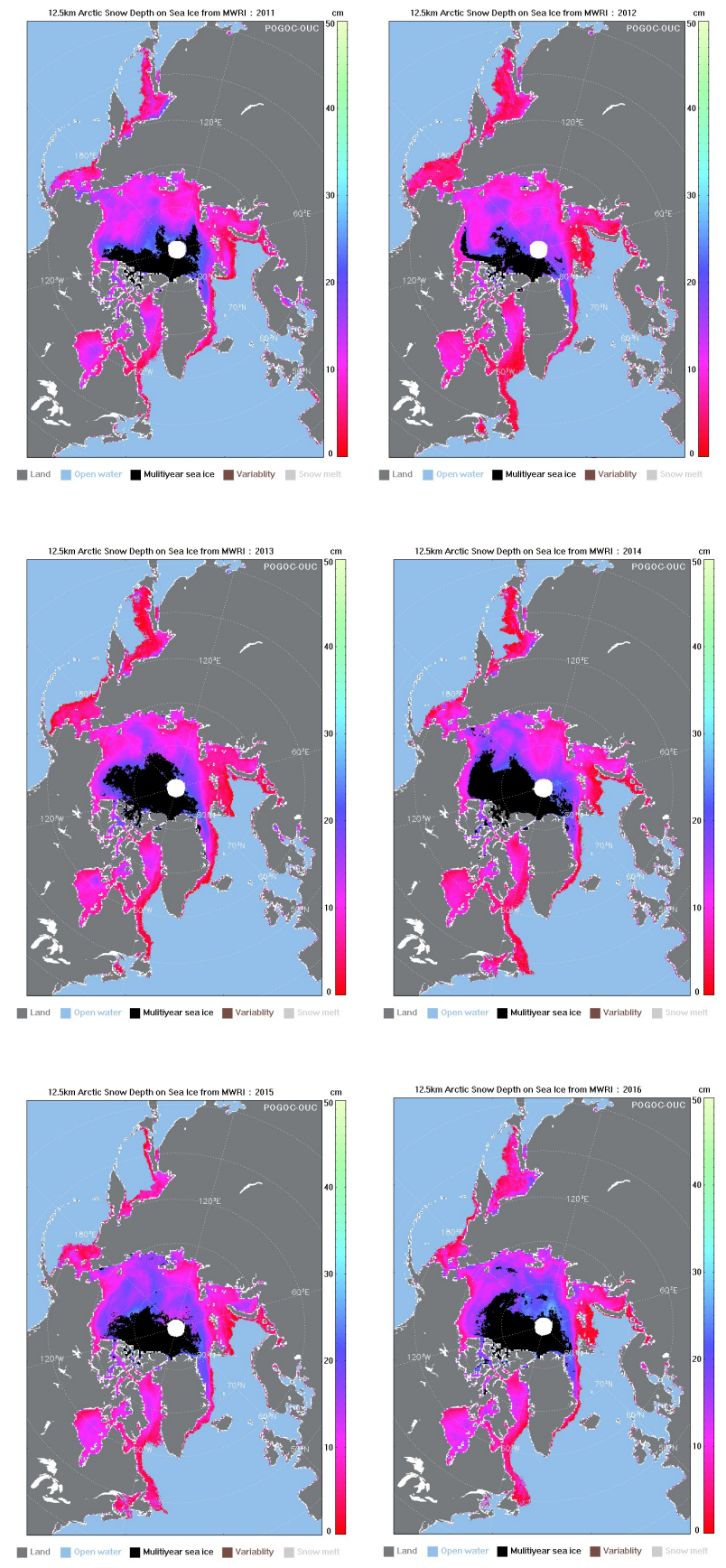
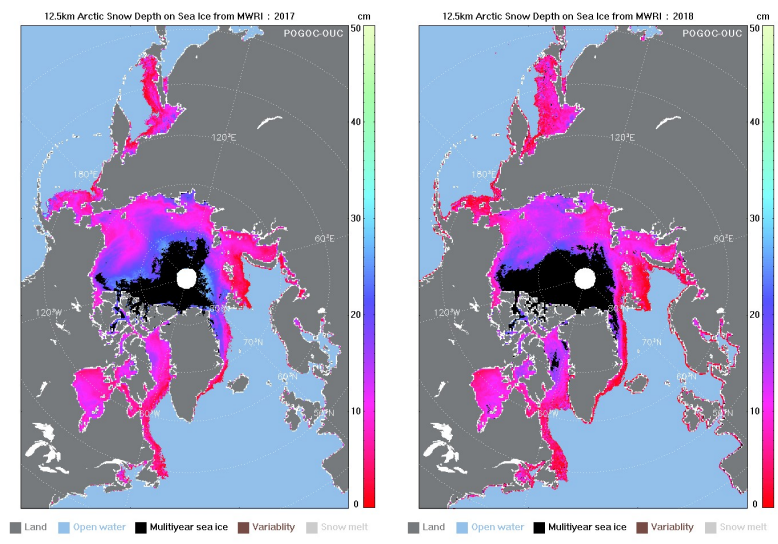

Figure 2. Annual distribution of snow depth on sea ice in the Arctic from 2011-2018

Figure 2 shows that the annual distribution of snow depth is similar to that of the monthly snow depth on first-year ice in the Arctic. The north of Canada and Greenland, close to the central Arctic, are covered with multiyear ice. The snow depths in areas close to the multiyear ice are relatively high compared with those in the East Siberian Sea and Beaufort Sea, which are higher than those in the Kara Sea, Laptev Sea, and Chukchi Sea in every year.

\subsection{Variations in Weekly Average Snow Depth}

Based on the snow depth product, we now analyze the spatial and temporal variations in snow depth. For this, we averaged the weekly, monthly and annual snow depth to give a mean value, and plot the values against time in Figures 3 to 5 .

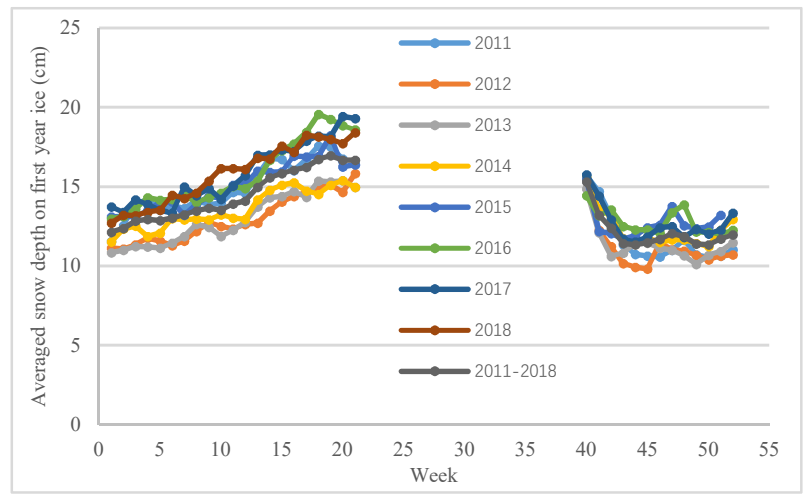

Figure 3. Weekly averaged snow depth on Arctic first-year ice from 2011-2018

From June-September every year, the snow on sea ice is melting in the Arctic. Using the existing microwave radiometer data, we cannot accurately detect the depth of wet snow. Therefore, the snow depth data from June-September are meaningless, and are not included in the analysis.

Figure 3 shows that:

1) In each year, the trend in the variation of snow depth on firstyear ice is almost the same.

2) The mean snow depth begins to increase from 
October/November due to snowfall, and reaches a maximum value in late April/early May of the next year.

3) After the period of snow melting in summer, the ice begins to freeze again in October every year.

\subsection{Monthly and Annual Variations}

To understand the monthly and annual variations in snow depth on first-year ice more intuitively, the difference in monthly average snow depths is used to analyze the monthly changes in snow depth, and the annual variations in snow depth are analyzed in terms of the difference in annual average snow depth.

Three months in spring and autumn are taken as examples to display the distribution of monthly snow depth differences, as shown in Figure 5.
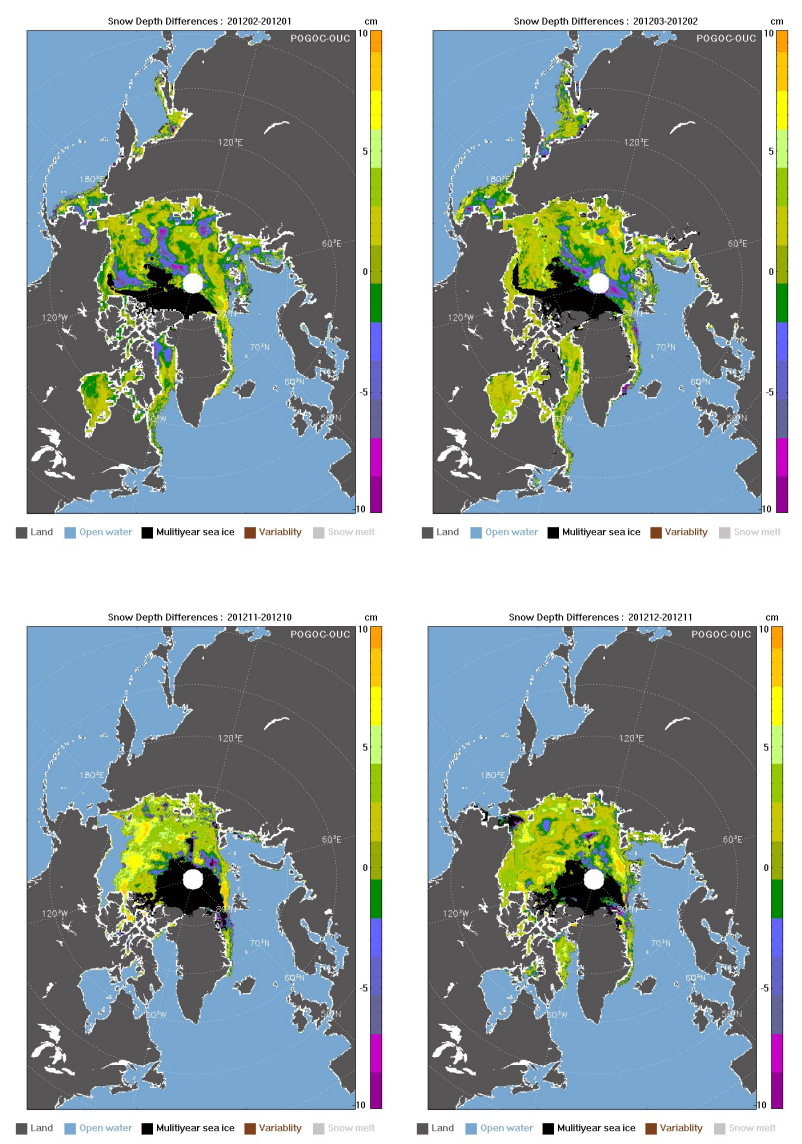

Figure 5. Variability in snow depth from January-March and from October-December of 2012

To further analysis the monthly variation of snow depth, we averaged the monthly snow depth to give a mean value, and plot the values against time in Figures 6.

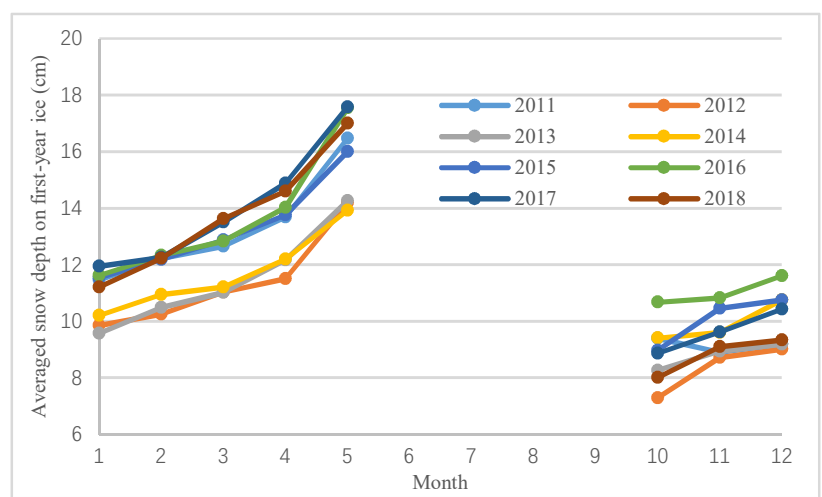

Figure 4. Monthly averaged snow depth on Arctic first-year ice from 2011-2018

From Figures 5 and 6, we can see that the snow depths on firstyear ice in the Arctic gradually increase in spring. After the freezing of first-year ice in October, the snow begins to accumulate at a higher speed than in spring. In spring, the fastest rate of change in snow depth occurs in the Chukchi Sea and East Siberian Sea, while in autumn, the Beaufort Sea, East Siberian Sea, and central Arctic exhibit the most rapid changes.

The variability in snow depth between 2011-2018 is shown in Figure 7.
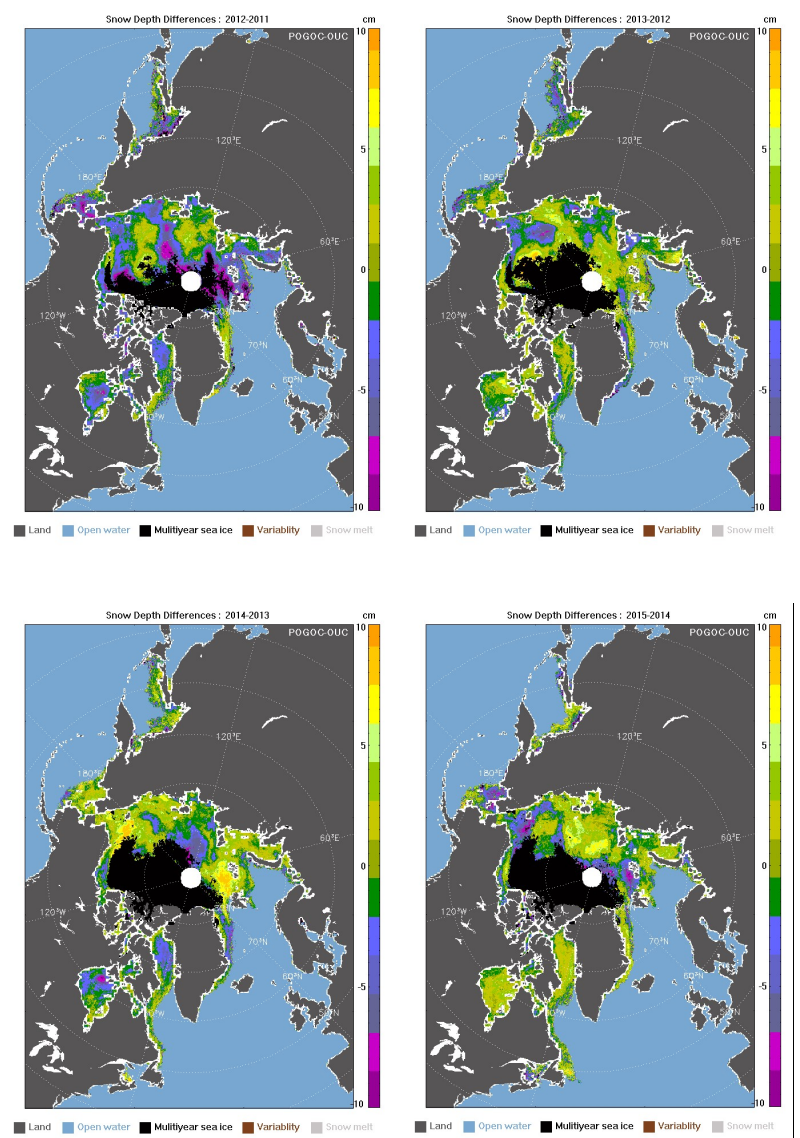

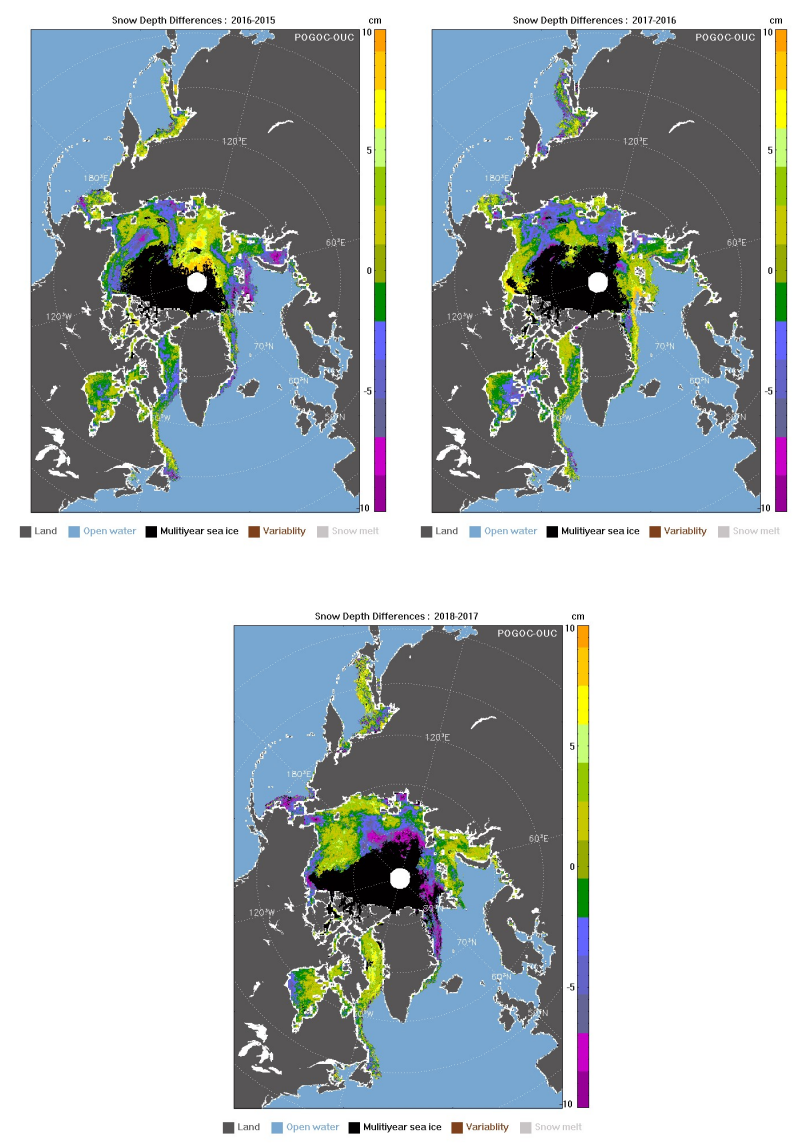

Figure 7. Variability in snow depth from 2011-2018

The annual analysis shows that there is no obvious law governing the inter-annual variations in snow depth. In some years, the annual variation in snow depth is largest in the Chukchi Sea, whereas in other years, the variations are largest in the Laptev Sea or the central region of the Arctic. Moreover, the snow depth in different seas may increase or decrease from year to year. However, the difference in the average snow depth between successive years is always less than $10 \mathrm{~cm}$.

\section{CONCLUSION}

In this study, we used the snow depth product published by Ocean University of China to analyze the temporal and spatial variations in snow depth on first-year ice in the Arctic. The analysis focused on the distribution features of snow depths, the change in the weekly average snow depths, and the variation in monthly and annual snow depths.

From the analysis, we can conclude that the distribution features of snow depth vary little by month or year. The snow depths in areas close to multiyear ice are typically higher than in other seas around the Arctic. Each year, the mean snow depth begins to increase from October/November and reaches a maximum value in late April/early May of the next year. In April, the snow begins to melt from low latitudes and the sea-land boundary areas, and this gradually extends to more central areas. After the period of snow melting in the summer, ice begins to freeze again in October and snow begins to accumulate. By the end of November, the snow covers the whole Arctic, and the snow depth increases over time each year. The rate of growth in snow depth is higher in autumn than in spring, and there is no obvious law governing the inter-annual variations in snow depth.

\section{ACKNOWLEDGEMENTS}

This work is supported by the National Key Research and Development Program of China (No. 2016YFC1402704, No. 2018YFA0605901).

\section{REFERENCES}

Chen, H.H., Tang, X.T., Li, L.L., Guan, L., 2019: Intercalibration of passive microwave brightness temperature observed by FY-3B/MWRI and Aqua/AMSR-E on Arctic. 2019 IEEE International Geoscience and Remote Sensing Symposium (IGARSS 2019). 8928-8931. doi.org/10.1109/igarss.2019.8899835.

Li L.L., Chen H.H, Guan L., 2019a: Retrieval of snow depth on sea ice in the Arctic using the FengYun-3B Microwave Radiation Imager. Journal of Ocean University of China, 18(3), 580-588. doi.org/10.1007/s11802-019-3873-y.

Li, L.L., Chen, H.H., Wang, X.Y., Guan, L., 2019b: Study on the retrieval of sea ice concentration from FY3B/MWRI in the Arctic. 2019 IEEE International Geoscience and Remote Sensing Symposium (IGARSS 2019). 4242-4245. doi.org/10.1109/igarss.2019.8900152.

Markus T., Cavalieri D.J., 1998: Snow depth distribution over sea ice in the Southern Ocean from satellite passive microwave data. In Antarctic Sea Ice: Physical Processes, Interactions and Variability, Antarctic Research Series, 74, 19-39. doi.org/10.1029/ar074p0019.

Meier W.N., Markus T., Comiso J.C., 2018: AMSR-E/AMSR2 Unified L3 Daily $12.5 \mathrm{~km}$ Brightness Temperatures, Sea Ice Concentration, Motion \& Snow Depth Polar Grids, Version 1. NASA National Snow and Ice Data Center Distributed Active Archive Center, Boulder, Colorado, USA. doi.org/10.5067/RA1MIJOYPK3P.

Yang, H., Weng, F.Z. Lv, L.Q., Lu, N.M., Liu, G.F., Bai, M., Qian, Q.Y., He, J.K., Xu, H.X., 2011: The Feng-Yun-3 microwave radiation imager on-orbit verification. IEEE Transactions on Geoscience and Remote Sensing, 39(11), 45524560. doi.org/10.1109/TGRS.2011.2148200. 